\title{
Optimizing Airlift Pumps for Aquaculture Applications
}

\author{
Shaker S. Bukhari, Wael H. Ahmed \\ University of Guelph \\ 50 Stone Rd E, Guelph, Canada \\ shaker@uoguelph.ca; ahmedw@uoguelph.ca
}

\begin{abstract}
The performance of airlift pump is dependent on the complex two-phase flow analysis that has yet not been optimized to its full potential for aquaculture applications. In this study, initial effort on the optimization of airlift pump performance for the highest efficiencies has been carried out. Two different optimization techniques were used in the present study including the minimum of constrained nonlinear multivariable function and the Genetic Algorithm. Both method were evaluated experimentally at different pump operating conditions. The experimental results show reasonable agreement with the Genetic Algorithm over a wide range of submergence ratio and air flow rates. Although, the optimization algorithms found to offer simple analysis when trying to setup an airlift pump for an aquaculture application, however, two-phase flow modelling taking into account the operating flow pattern is considered to be the best in evaluating the airlift pump performance.
\end{abstract}

Keywords: Airlift pump, Aquaculture, Two-phase flow, Optimization, Genetic algorithm

\section{Introduction}

Airlift pumps have been an integral part of many industries and applications. The earliest recordings of airlift pump uses were by a mining engineer in Germany, Carl E. Loescher, in 1797 who came up with the concept of the airlift pump as stated by Castro [1]. An airlift pump is a mechanically simple pump with no moving parts. It consists of a vertical pipe that is partially submerged in a vessel or a well that contains liquid or a mixture of liquid and solid particles and air injector. The air is injected at the bottom of the pipe or at a submerged level creating lower density mixture of gas and liquid that induce a buoyancy force, which in turn pumps the liquid or the liquid-solid mixture to the top of the pipe [2].

Moreover, applications of airlift pumps have been noted in the oil industry as early as 1847 in USA. They have also been used in aquatic research to retrieve seawater samples. Sewage treatment facilities have also been using airlift pumps for pumping, aeration and desertification processes [3]. Airlift pump's industrial applications are vast including aquaponics, hydroponics, agriculture, sanitation, food processing, chemical processing and others.

The examination conducted by Wurts et. al [4] to better understand the airlift pumps for aquaculture industry shows a positive and huge potential for this application. Another study conducted by Barrut et al. [5] shows that vacuum airlift pumps are quite effective at evacuating aquaculture tanks from the undesirable particles (uneaten feed, faecal matter, etc.). Moreover, with the exponential growth that has been notice in aquaculture over the last 5 decades and it now contributes to $50 \%$ of all global seafood production, the potential use of airlift pumps continue to grow [6]. It should be noted that the efficiencies of the aquaculture industries are much greater compared to meat production industry mainly because the feed to produce ratios are superior when dealing with fish and crustaceans. Also, energy consumption in aquaculture systems is more comparable to producing rice or wheat then other animal based production. This is one of the reasons why in recent years the demands for more fish farms and other aquaculture facilities have increased globally [7].

The productivity of aquaculture facilities heavily relies on circulation and aeration of fish tanks. The movement of the water and the addition of air decrease the stratification of harmful particles, improve the solubility of nutrients, and lessen the accumulation of organic material at the lower levels of the tank. These factors improve the production and quality of the fish [3]. On the other hand, aeration is crucial in aquaculture for the oxygenation of the tanks. Sources from the Department of Fisheries and Aquatic Sciences in Florida found that the dissolved oxygen level should be over $60 \%$ for most cases in fish farming in order to have healthy produce. Most of airlift pumps have been found to achieve this criteria and percentages of oxygen [8]. Another study was conducted on an endangered species of fish named the Rio Grande silvery minnow where they implemented airlift pumps to circulate and aerate a round tank that contained the fish. They 
found that the survival rate of the fish exceeded expectations and the use of airlift pumps was proved to be a safe and inexpensive solution for the required application [9]. Also, the research conducted by Barrut et al. [10] looked at the mass transfer efficiencies of vacuum airlift pumps for water circulation in aquaculture tanks and found that the system requires $40 \%$ less energy when compared to conventional centrifugal pumps for low head applications.

In general, fish farms do not require very high water head or relatively high flowrates. However, it is very important in aquaculture to have the water in constant motion with sufficient current as well as maintain the oxygen level at acceptable range. For example; in recirculating aquaculture systems multiple parameter criteria must be satisfied for any designated species to grow in a healthy and safe manner, some parameters more crucial than others depending on how long the livestock can handle insufficiencies in the system. Oxygen level is the first most dramatic parameter that must be kept over a certain amount before leading to disease, stress or even lose in stock within a few minutes. Other important water quality parameters such as carbon-dioxide, ammonia, alkalinity and $\mathrm{pH}$ levels, can affect the aquatic life's health depending on species. Loyless and Malone [11] discuss the effect of water quality parameters and how effective airlift pumps could be used to maintain all the required levels for the aquaculture system. They conducted experiments using airlift pumps that utilise air-stone as an injector or no air-stone at the inlet of the pump. Their goal was to determine how satisfactory gas transfer levels could be by only using the airlift. Their results showed that airlift pumps with air-stones do achieve more oxygen and other gas transfer but require more power to perform. On the other hand, airlift pumps with no air-stones have lower gas transfer rates but are much more efficient at moving the water in the tank which is also an important parameter to have in recirculating aquaculture systems. It has been also concluded that if these airlifts are optimized in design and operation they could replace other methods of achieving these desired conditions $[8,11-13]$

It has been concluded by many studies that airlift pumps run at maximum performance if operated at the slug flow pattern conditions. In this case, the air bubbles "slugs" are almost in the same sizes as the pipe diameter making them ideal for pushing the liquid up the pipe as if they were pistons pumping the water to the top of the pipe [14-16]. Looking at the other flow patterns, it can be seen why it would not be ideal if the airlift pump run in those flow patterns. For example if the flow is annular the liquid is lifted under the effect of shear forces between the gas the liquid interface. On the other hand, the closest performance to the maximum is found for churn flow pattern [15].

Recently, Ahmed et al. evaluate the performance of airlift pump with different air injections method. One successful modification in the injection is adapting a dual injection mode to achieve higher water flow rates or maximum efficiency. They also investigated the effect of four injector designs on the pump performance including radial injection, axial injection, swirl injection and dual injection. The results of this study show that dual injection which is a combination of radial and axial had the superior performance over the rest. The study also investigated the effect of air pulsation and found it to affect the pump performance positively [16]. These air injection technologies are also patented by Badr and Ahmed [17] which show a promising future for aquaculture applications.

The main objective of this study is to identify the best design parameters for airlift pump in order to achieve the maximum possible efficiency at the desired operating conditions. Different optimization techniques will be investigated using the model developed by Kassab et al. [18]. Experiments will be performed for different air and water flow rates and submergence ratios. The optimization results will be validated using the experimental data in order to identify best conditions commonly required for the aquaculture industry.

\section{Methodology}

Optimization is considered as a general design process where a set of parameters that must obey certain constraints that are applied to a design and an optimal solution for that design within those constraints will be located. There are multiple different methods to locate this optimal solution. In general, all optimization problems must be converted to the standard optimization form initially as suggested by Arora [19]. Therefore, the objective function must be defined in the beginning and will always be a minimization function that can be written as follows:

$$
f(x)=f\left(x_{1}, x_{2}, \ldots, x_{n}\right)
$$

and will be subjected to the $(p)$ equality constraints:

$$
h_{j}(x)=h_{j}\left(x_{1}, x_{2}, \ldots, x_{n}\right)=0 ; \quad i=1 \text { to } p
$$


and the $(m)$ inequality constraints:

$$
g_{j}(x)=g_{j}\left(x_{1}, x_{2}, \ldots, x_{n}\right) \leq 0 ; \quad j=1 \text { to } m
$$

In this minimization process maximum efficiency is required and therefore the object function will be multiplied by (1) to convert the optimization into a maximization process [19].

In the first method, the minimum of constrained nonlinear multivariable function will be simply represented as "fmincon" which is also the syntax of the function in MATLAB ${ }^{\odot}$. This optimization technique is found to be the most basic ways to find an optimized solution for a problem. This method uses a numerical search iteratively in the feasible region defined by the constraints, until the optimum solution is found. During the optimization process, a search in a matrix of given values that would be constrained and a test of each value into the objective function will be performed. If a local minimum is found, the search will terminate and the final optimum solution will be identified. In this method, the solution could converge prematurely into a local minimum that would not be the global minimum and leads to inaccurate result. Therefore the constraints provided to the system must be very concise. The function "fmincon" uses the finite difference method to calculate the numerical gradient in the present case.

In the second method, genetic algorithm $(G A)$ developed based on the theory of evolution and natural selection, will be used. The GA is a smart random search in a specified domain that determines the optimal solution through multiple steps of populating the reproduction, random selections and mutations and survival of the best fitness [18, 19]. This method of optimization is known to be robust and versatile when used in optimizing engineering designs such as turbine blades, fins, flow control devices [20-22].In this method, random set of solutions were generated to set the starting population. Then, the selection of the parents was made based on their fitness in the objective function which will breed a new generation. The function will provide the optimum solutions when converge. The selection of the next generation crossovers where random pairs of parents are exchanged randomly. Now a new generation of solution is born and mutations are changed slightly until reach local minimum. The whole procedure is repeated until the new populations of optimum solution is obtained [20].

The objective function of the current optimization is the efficiency of the airlift pump. The efficiency is defined by the work required to move the liquid to the top of the pipe divided by the isothermal expansion work done by the gas. This definition was developed by Nicklin [14] and the efficiency expression can be written as:

$$
\eta=\frac{\rho g Q_{\mathrm{l}}\left(\mathrm{L}-\mathrm{H}_{\mathrm{s}}\right)}{\mathrm{P}_{\mathrm{a}} \mathrm{Q}_{\mathrm{g}} \ln \left(\frac{\mathrm{P}_{1}}{\mathrm{P}_{\mathrm{a}}}\right)}
$$

where $Q_{l}$ and $Q_{g}$ represent the volumetric flow rate of liquid and gas respectively. This will be considered to be the input variables required for the optimization processes. $\rho$ is the density of the liquid, $g$ is the gravitational acceleration, $P_{a}$ is the atmospheric pressure, $P_{1}$ is the gas pressure at the injector inlet, $L$ is the total length of the pipe, and $H_{s}$ is the static submerged head. Equation (4) will be the objective function, also called the fitness function and the optimization will be performed in order to maximize the efficiency $\eta$. Both equality constraints and inequality constraints are adjusted in order to complete the optimization process. The main equality constraint is determined using the airlift pump model of Kassab et al. [18]. This model incorporates one dimensional momentum and continuity equations as discussed in details by Clark and Dabolt [25]. The geometric parameters for each separate optimization case are the pipe diameter, D, the pipe length, L, the static head, $\mathrm{H}_{\mathrm{s}}$, and the main equation of the model is written as follows:

$$
\frac{H_{s}}{L}-\frac{1}{\left(1+\frac{Q_{g}}{s Q_{l}}\right)}=\frac{V_{1}^{2}}{2 g L}\left[(K+1)+(K+2) \frac{Q_{g}}{Q_{l}}\right]
$$

where $K$ represents a function of the friction factor $f$ : 


$$
\begin{gathered}
K=\frac{4 f L}{D} \\
f=0.25\left[\log \left(\frac{150.39}{R e^{0.98865}}-\frac{152.66}{R e}\right)\right]^{-2}
\end{gathered}
$$

The slip ratio $(s)$ between the phases for slug flow where the airlift pump best efficiency rage is suggested by Ahmed et al. [26] as follows:

$$
\begin{gathered}
s=1.2+0.2 \frac{Q_{g}}{Q_{l}}+\frac{0.35 \sqrt{g D}}{V_{1}} \\
V_{1}=\frac{Q_{l}}{A}
\end{gathered}
$$

This model can be solved iteratively to find the corresponding $Q_{l}$ for each given $Q_{g}$. This model will be used as the main constraint for the optimization techniques to have a strong relationship between $Q_{l}$ and $Q_{g}$. After the model is solved for each independent case of different $\left(D, L\right.$, and $\left.H_{S}\right)$ a curve is fitted to the model with an eighth polynomial degree for higher accuracy. The resulting function will serve as an equality constraint for the optimizations. For the inequality constraint, the bounds of the problem will be defined for each case by looking at the range of the model.

\section{Experimental Work}

An experimental setup was designed and built to validate the outcome of the optimization processes and shown in Figure 1. As shown in the figure, water is supplied from a tank that is connected to an over flow pipe to maintain the water supply at a constant head. The water turbulence of the water entering the supply tank is damped using rocks to maintain the smooth free water surface. The water enters the bottom of the pipe riser reaching the same static head level $\left(H_{S}\right)$ as in the supply tank. The injector is placed at a submerged level in the pipe riser. The air is supplied by a compressor after passing through a flowmeter that can control the amount of injected air flow rate. The water is pumped up through a total pipe length of $1.56 \mathrm{~m}(L)$ of transparent acrylic pipe with a diameter of $0.031 \mathrm{~m}(D)$ to the top of the pipe where a collection tank that is connected to the measuring tank. The volume of water collected is measured over time to determine the water flow rate. A capacitance sensor is installed on the airlift pipe riser and electrically connected to the data acquisition system where void fraction can be measured. Also, a high-speed camera is used to better visualize the air-water flow-patterns in the pipe downstream of the air injector. Multiple measurements have been collected at different submergence ratios and air flow rates. In this study, submergence ratios of $0.5,0.7$, and 0.9 were investigated. 


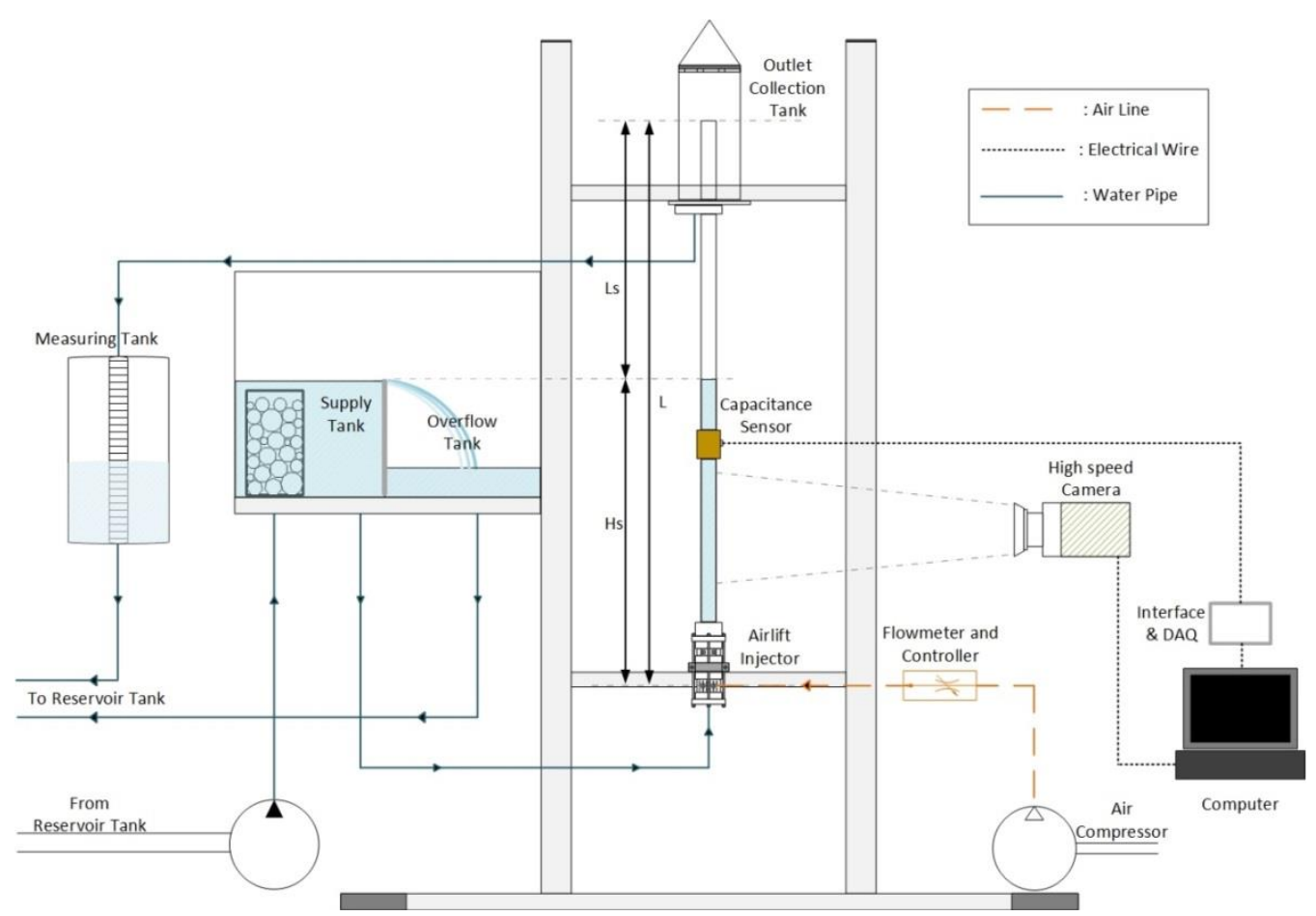

Fig. 1: Experimental setup illustration.

In this study, the observed flow patterns are bubbly, slug, churn flow and annular flow as shown in Figure 2. The optimum pump performance was found at the slug flow pattern as concluded by Ahmed et al. [16]. In this case, the slug starts to emerge from the injector pushing the water until the slug fills a section of the pipe creating the pumping effect.

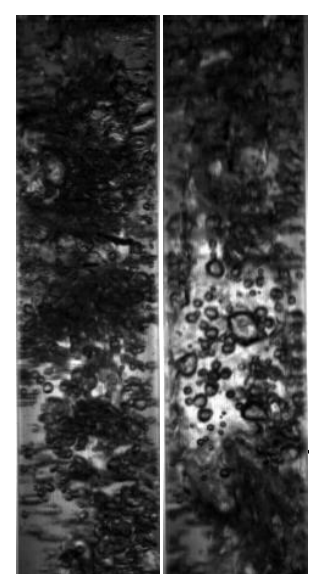

Bubbly and Churn flow

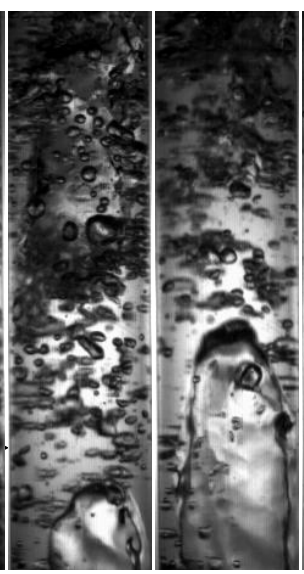

Slug and Churn flow

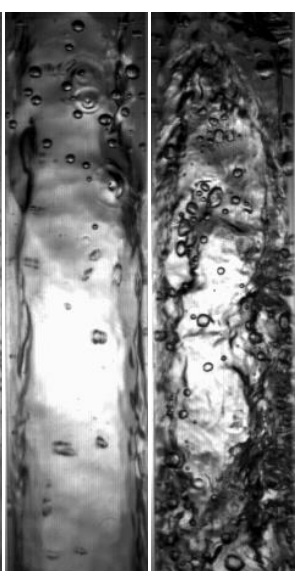

Annular wavy flow

Fig. 2: Flow pattern cycle of airlift pump.

\section{Results}

The performance of the airlift pump for submergence ratio of 0.5 is presented in Figure 3 in terms of the efficiency and water mass flow rate as a function of the air mass flow rate. Error analysis for the performance data was conducted and the percentage of error in each measurement is shown in Figure 3. The uncertainty analysis is calculated using the error propagation method. The uncertainty of the water mass flow rate found to be $\pm 15.14 \%$ and for the air flow rate is $\pm 1 \%$. As shown Figure 3, the highest efficiency is not located at the highest water mass flow rate. Therefore, the methods used in the present study is strictly optimize for efficiency only for energy conscious purposes. The results of both optimization methods including fmincon and GA are compared to the experimental data and shown in Figure 4. The geometrical 
parameters of the system are set up to optimize for the high efficiency. In general, the prediction of both methods are considered comparable, however, the GA shows a better prediction than the fmincon especially at the 0.5 submergence ratio and slightly better in 0.7 and 0.9 submergence ratio.

As shown in Figure 4, the large deviation for the 0.7 submergence ratio is due multiple factor including the lack of large number of collected data and the model representing the constraint relationship cannot accurately predict the flowrates. This might mean that there are limitations on the model, however the results presented here are preliminary and better model must be developed to properly explain the physical phenomena occurring in the airlift. This error could be also attributed to the curve fitting used for the equality constraints. The overall results provide a good representation of the expected efficiencies at these geometrical conditions. Different scenarios using the GA were performed to in order to find different geometrical design condition for the same high efficiencies. Figure 5 shows the efficiencies for a dimeter pipe of $0.031 \mathrm{~m}$ and varying lengths through the GA for a given submergence ratio. Figure 6 shows the efficiencies for a pipe length of $1.56 \mathrm{~m}$ and varying diameters through the GA for a given submergence ratio. Both Figures 5 and 6 shows that the design parameters of airlift pumps can be estimated for desired efficiencies and for required submergence ratios.

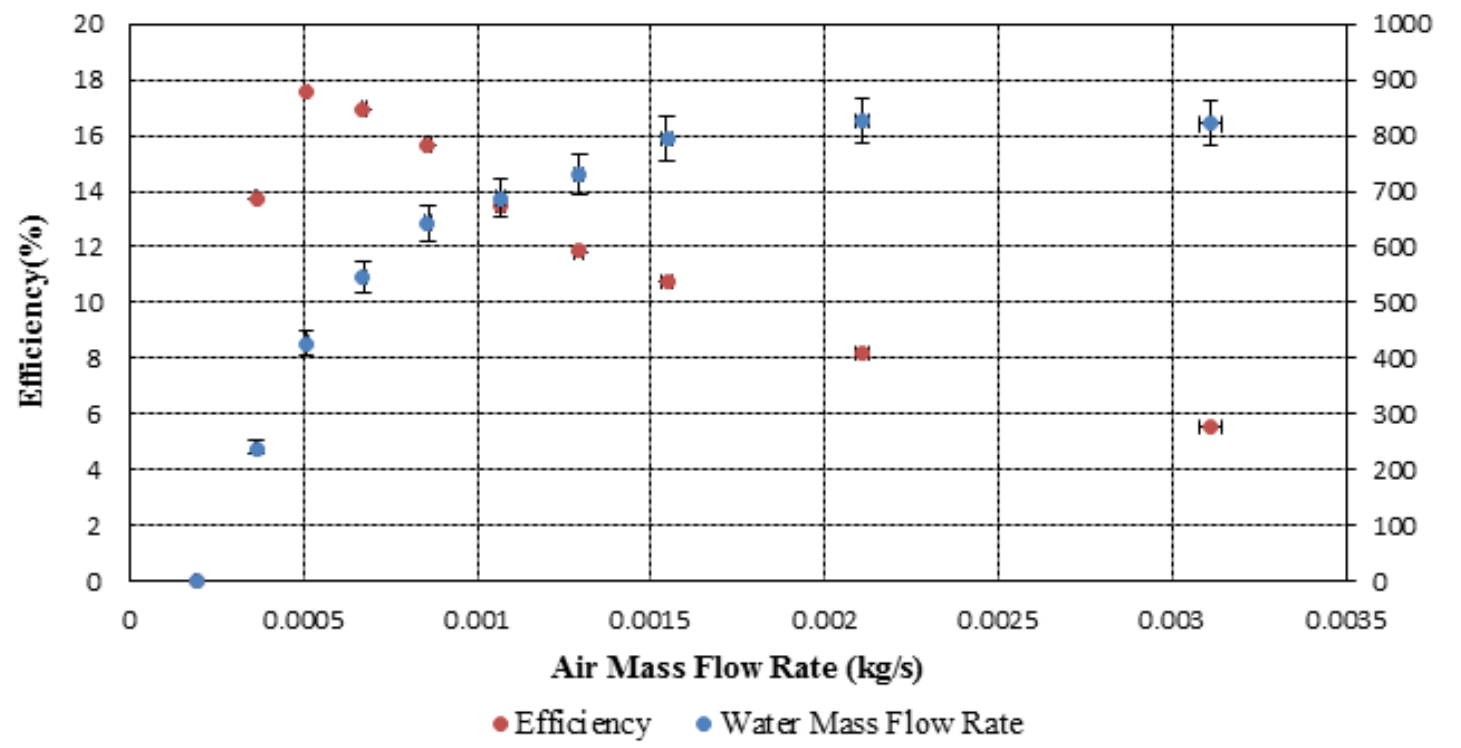

Fig. 3: Performance of the airlift pump.

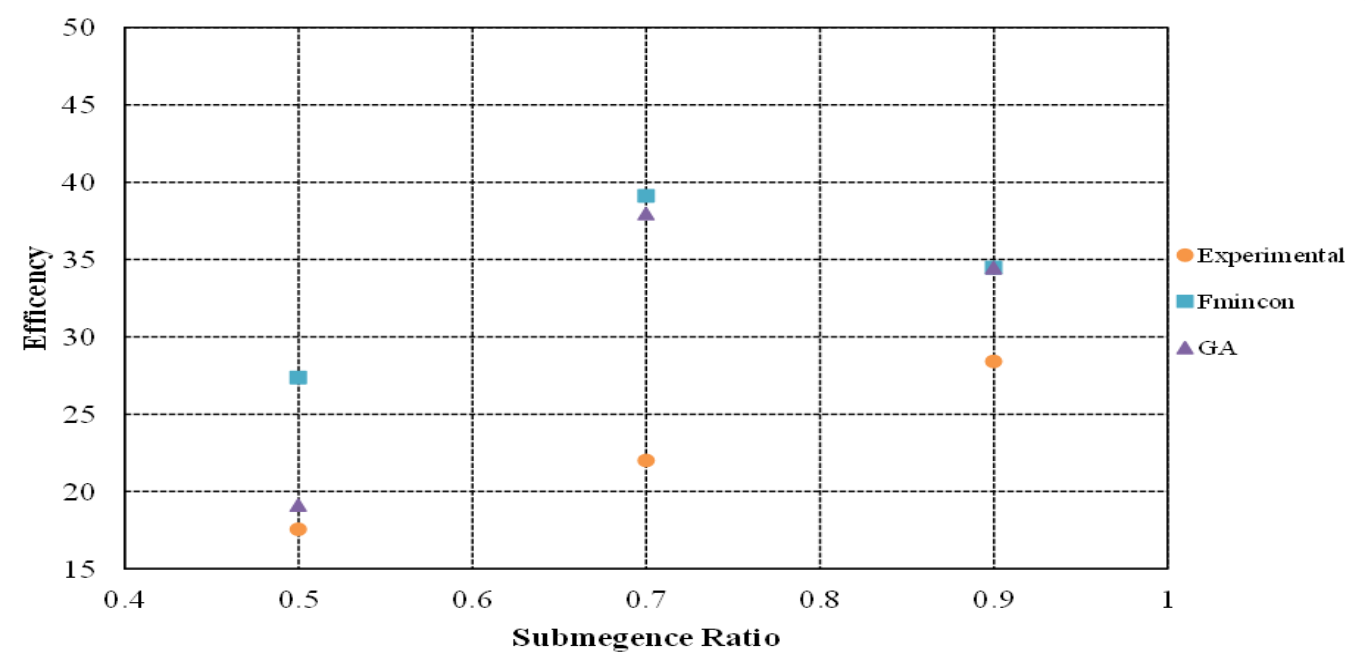

Fig. 4: Optimal Efficiency comparison for $\mathrm{D}=0.03175 \mathrm{~m}, \mathrm{~L}=1.5673 \mathrm{~m}$. 


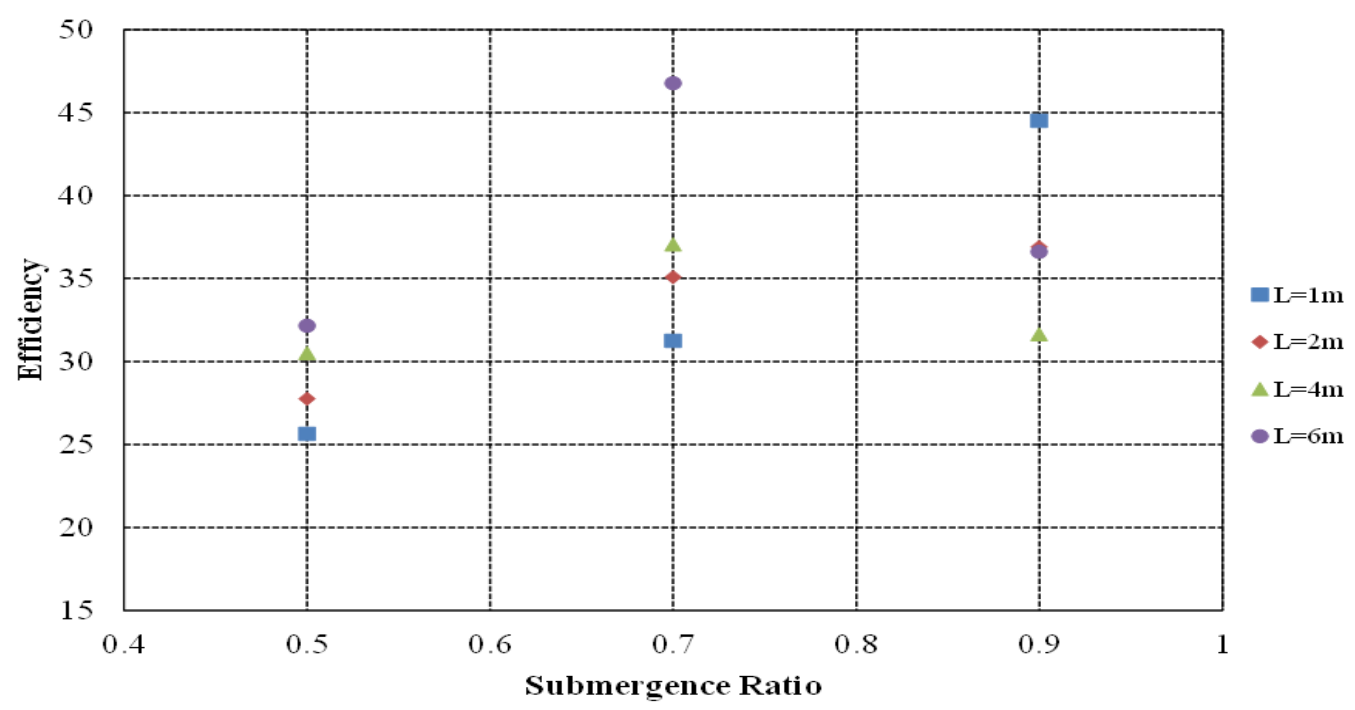

Fig. 5: Optimal Efficiencies for constant $\mathrm{D}=0.03175 \mathrm{~m} G A$ method.

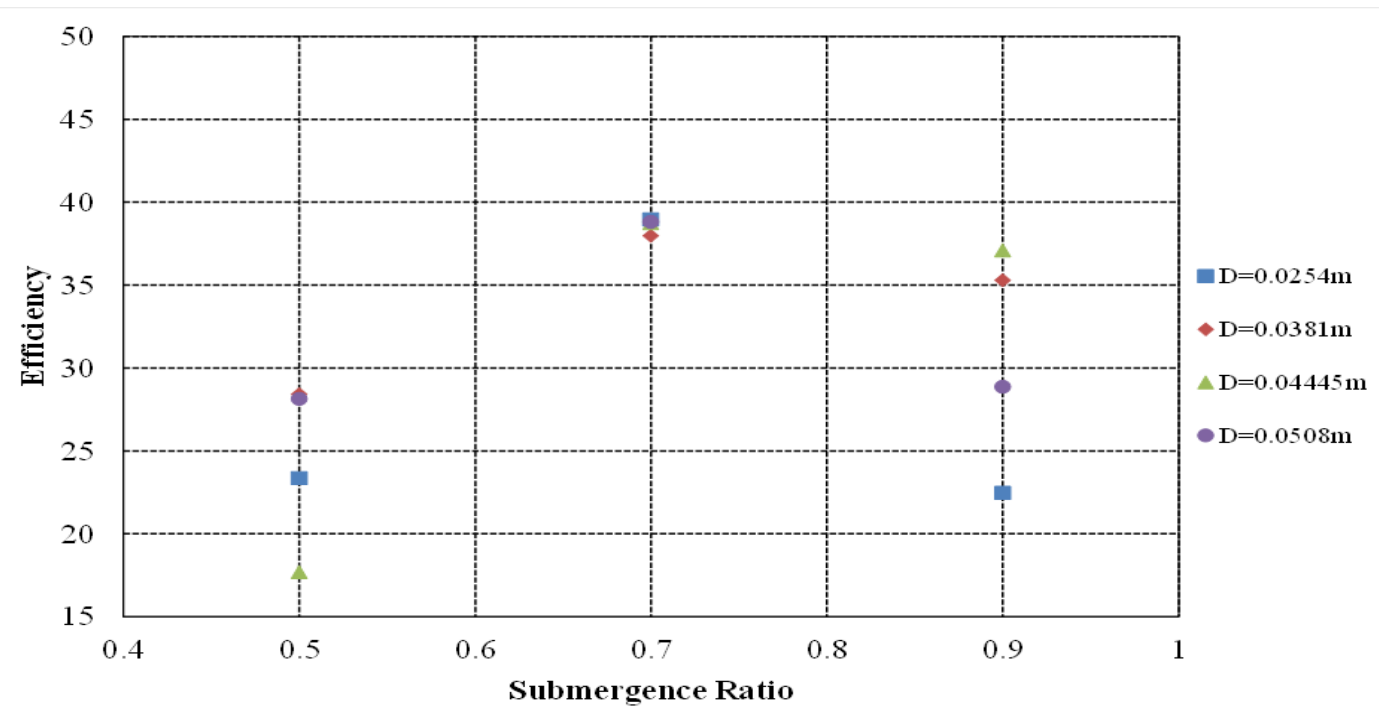

Fig. 6: Optimal Efficiencies for constant $\mathrm{L}=1.5673 \mathrm{~m} G A$ method.

\section{Conclusion}

The present study shows that optimization process is a simple option that can be used to design airlift pump for aquaculture applications. The results show a favourable outcome when compared to experimental. The results indicate that optimization methods can predict the highest efficiencies when working at smaller submergence ratios. The $G A$ method proves to be more robust for locating the optimal conditions when compared to the real data. The optimization algorithms found to offer simple analysis when trying to setup an airlift pump for an aquaculture application. However, two-phase flow modelling taking into account the operating flow pattern and the interfacial parameters between phases is still considered a better tool in predicting the airlift pump performance

\section{References}

[1] W. E. Castro, P. B. Zielinski, and P. A. Sandifer, "Performance Characteristics of Air Lift Pumps of Short Length and Small Diameter," Proc. Annu. Meet. - World Maric. Soc., vol. 6, no. 1-4, pp. 451-461, 2009.

[2] S. K. OH, "Performance of Airlift Pump for Water Circulation and Aeration," Bull. Korean Fish. Dep. Mar. Eng. 
Tong Natl. Fish. collage Chungmu, vol. 25, no. 6, p. 529-537, 1992.

[3] N. C. Parker and M. A. Suttle, "Design of Airlift Pumps for Water Circulation and Aeration in Aquaculture," vol. 6, pp. 97-110, 1987.

[4] W. A. Wurts, S. G. Mcneill, and D. G. Overhults, "Performance and design characteristics of airlift pumps for field applications," vol. 25, no. December, pp. 51-55, 1994.

[5] B. Barrut, J. Blancheton, M. Callier, J. Champagne, and A. Grasmick, "Aquacultural Engineering Foam fractionation efficiency of a vacuum airlift:Application to particulate matter removal in recirculating systems," Aquac. Eng., vol. 54, pp. 16-21, 2013.

[6] H. E. Froehlich, R. R. Gentry, and B. S. Halpern, "Synthesis and comparative analysis of physiological tolerance and life-history growth traits of marine aquaculture species," Aquaculture, vol. 460, pp. 75-82, 2016.

[7] D. J. Reinemann, "A Theoretical And Experimental Study of Airlift Pumping and Aeration with Reference to Aquacultural Applications," Ph.D. Thesis, Cornell University, 1987.

[8] M. Mcgee and C. Cichra, "Principles of Water Recirculation and Filtration in Aquaculture 1," Univ. Florida, Dept. Fisheries Aquatic Sci., Florida Coop. Ext. Serv. FA-12, 2000.

[9] D. Tave, L. Valenzuela, L. Toya, and A. M. Huston, "New Design for Airlift Pump Used in Fish Culture Tanks with Endangered Rio Grande Silvery Minnow (Hybognathus amarus)," Croat. J. Fish., vol. 70, no. 3, pp. 83-91, 2012.

[10] B. Barrut, J. Blancheton, J. Champagne, and A. Grasmick, "Mass transfer efficiency of a vacuum airlift Application to water recycling in aquaculture systems," Aquacultural Engineering, vol. 46, pp. 18-26, 2012.

[11] J. C. Loyless and R. F. Malone, "Evaluation of air-lift pump capabilities for water delivery , aeration , and degasification for application to recirculating aquaculture systems," Aquac. Eng., vol. 18, pp. 117-133, 1998.

[12] J. S. Pade, “Aquaponic Equipment -Airlifts-," Aquaponics J., pp. 24-25, 2008.

[13] B. Durborow, "Kentucky Aquatic Farming," Kentucky State University, vol. 27, no. 1, 2014.

[14] D. J. Nicklin, "The Air-Lift Pump: Theory and Optimisation," Chem. Eng. Res. Des., vol. 41, 1963.

[15] F. De Cachard and J. M. Delhaye, "A Slug-Churn Flow Model for Small-Diameter Airlift Pumps," Int. J. Multiph. Flow, vol. 22, no. 4, pp. 627-649, 1996.

[16] W. H. Ahmed, and H. M. Badr, "Dual-Injection Airlift Pumps : An Enhanced Performance Dual-Injection Airlift Pumps : An Enhanced Performance," Particulate Sci, Techno., vol. 6351, no. February, 2016.

[17] H. M. Badr and W. H. Ahmed, US PatentUS 2012 /0308407 A1, 2012.

[18] S. Z. Kassab, H. A. Kandil, H. A. Warda, and W. H. Ahmed, "Air-lift pumps characteristics under two-phase flow conditions," Int. J. Heat Fluid Flow, vol. 30, pp. 88-98, 2009.

[19] J. S. Arora, "Introduction to Optimum Design," Academic Press, Elsevier Inc., 2012.

[20] P. Bajpai and M. Kumar, "Genetic Algorithm - an Approach to Solve Global Optimization Problems," Indian J. Comput. Sci. Eng., vol. 1, no. 3, pp. 199-206, 2010.

[21] C. Feng, L. Liu, and S. A. Burns, "Using Genetic Algorithms to Solve Construction Time-Cost Trade-off Problems," J. Comput. Civil. Eng., vol. 11, no. 3, pp. 184-189, 1997.

[22] M. A. Trigg, G. R. Tubby, and A. G. Sheard, "Automatic Genetic Optimization Approach to Two-Dimensional Blade Profile Design for Steam Turbines," Journal of Turbomachinery, vol. 121, no. January, pp. 11-17, 1999.

[23] M. Milano and P. Koumoutsakos, "A Clustering Genetic Algorithm for Cylinder Drag Optimization," Journal of Computational Physics, vol. 107, pp. 79-107, 2002.

[24] C. Poloni, A. Giurgevich, L. Onesti, and V. Pediroda, "Hybridization of a multi-objective genetic algorithm , a neural network and a classical optimizer for a complex design problem in fluid dynamics," Comput. Methods Appl. Mech. Engrg., vol. 186, pp. 403-420, 2000.

[25] N. N. Clark, J. W. Van Egmond, and E. P. Nebiolo, "The Drift-Flux Model Applied To Bubble Columns And Low Velocity Flows," Int. J. Multiph. Flow, vol. 16, no. 2, pp. 261-279, 1990.

[26] W. H. Ahmed, A. M. Aman, H. M. Badr and A. M. Alqutub, "Air injection methods: The key to a better performance of airlift pumps," Experimental Thermal and Fluid Science, vol. 70, pp. 354-365, 2016. 